Uma Abordagem Interdisciplinar sobre Qualidade da Água como Estratégia para o Ensino de Ciências

\author{
Anacleto, R. G.; Bilotta, P.*
}

Rev. Virtual Quim., 2015, 7 (6), 2622-2634. Data de publicação na Web: 3 de novembro de 2015

\author{
http://www.uff.br/rvq
}

\title{
An Interdisciplinary Approach about Water Quality as Strategy for Science Education
}

\begin{abstract}
The aim of this work is to present an interdisciplinary tool for addressing chemical, biology, physics and geography contents for teaching water quality. The tool was structured in two parts: 1) input data from chemical, physical, biological, geographical, and observation parameters (require the participation of the student to obtain information about the local river); 2) storage and analysis of the data (integrate the practice and the theoretical contents). As conclusion, the following aspects were identified about the tool: simple use, accessible to any computer with minimum configuration, dispense connection to internet, can be modified according to the regional specificities of the country, can be updated with no cost, develop an interdisciplinary and global view about water pollution in the student.
\end{abstract}

Keywords: Science education; water quality; chemical, physical and biological parameters; BVI.

\section{Resumo}

O objetivo deste trabalho é apresentar uma ferramenta interdisciplinar para abordar conteúdos de química, biologia, física e geografia para o ensino de qualidade da água. A ferramenta foi estruturada em duas partes: 1) entrada de dados de parâmetros químicos, físicos, biológicos, geográficos e de observação (requer a participação do aluno para obter informações sobre os rios de sua comunidade); 2 ) armazenamento e análise dos dados (integra a prática e o conteúdo teórico). Como conclusão, foram identificados os seguintes aspectos relativos à ferramenta: facilidade de uso, acessibilidade a qualquer computador minimamente configurado, dispensa conexão com internet, pode ser modificada de acordo com as especificidades regionais do país, pode ser atualizada sem qualquer custo, desenvolve uma visão interdisciplinar e global da poluição das águas no aluno.

Palavras-chave: Educação de ciências; qualidade da água; parâmetros químicos; físicos e biológicos; IQA; IBVol.

\footnotetext{
* Universidade Positivo, Programa de Mestrado e Doutorado em Gestão Ambiental, Rua Prof. Pedro Viriato Parigot de Souza, 5300, CEP 81280-330, Curitiba, Paraná.

Mpb.bilotta@gmail.com DOI: $10.5935 / 1984-6835.20150156$
} 


\title{
Uma Abordagem Interdisciplinar sobre Qualidade da Água como Estratégia para o Ensino de Ciências
}

\author{
Radamés G. Anacleto, ${ }^{a}$ Patrícia Bilotta ${ }^{\mathrm{b}, *}$ \\ a Universidade Positivo, Departamento de Ciências Biológicas, Rua Prof. Pedro Viriato Parigot \\ de Souza, 5300, CEP 81280-330, Curitiba-PR, Brasil. \\ ${ }^{\mathrm{b}}$ Universidade Positivo, Programa de Mestrado e Doutorado em Gestão Ambiental, Rua Prof. \\ Pedro Viriato Parigot de Souza, 5300, CEP 81280-330, Curitiba-PR, Brasil. \\ * pb.bilotta@gmail.com
}

Recebido em 24 de setembro de 2015. Aceito para publicação em 3 de novembro de 2015

\section{Introdução}

2. A interdisciplinaridade como estratégia de ensino

3. Práticas de ciências em uma abordagem interdisciplinar

4. Desenvolvimento da proposta do trabalho

5. Resultados e discussão

5.1. Etapa 1: Caracterização físico-química e biológica da água

5.2. Etapa 2: Determinação do Índice IBVol

5.3. Etapa 3: Caracterização da vizinhança do corpo hídrico

5.4. Etapa 4: Glossário

5.5. Etapa 5 e Etapa 6: Legislação e material suplementar

\section{Conclusão}

\section{Introdução}

A poluição hídrica é um problema grave de saúde pública que atinge milhares de pessoas em cidades brasileiras. Esse fenômeno decorre, quase sempre, do descarte inadequado de efluentes contaminados, provenientes de atividades diversas, como esgoto doméstico, industrial e dejeto animal, que podem provocar alterações na qualidade química (redução de oxigênio dissolvido pela presença de substâncias orgânicas biodegradáveis e acúmulo de compostos inorgânicos persistentes que oferecem riscos à cadeia alimentar), física (por exemplo, aumento da temperatura) e biológica (acúmulo de microrganismos patogênicos causadores de doenças) da água. ${ }^{1,2}$ As alterações provocadas por essas vias podem influenciar negativamente nos processos físico-químicos que ocorrem em cursos d'água e interferir no metabolismo e, até mesmo, na diversidade de organismos que ali desempenham papel ecológico. $^{2}$ 
A contaminação pode se dar por fontes pontuais lançadas em determinados pontos do corpo d'água (por exemplo, lançamento de esgoto sanitário a partir de uma rede coletora) e por fontes difusas que alcançam os cursos d'água de forma dispersa (por exemplo, escoamento superficial de resíduos de fertilizantes e defensivos agrícolas, de dejetos do confinamento animal e da poluição das vias públicas urbanas). ${ }^{3}$

A identificação das fontes poluidoras, pela fiscalização, e a aplicação de penalidades previstas na legislação são instrumentos indispensáveis na gestão e conservação da qualidade dos recursos hídricos. ${ }^{4}$ Para dar suporte às ações de fiscalização, a verificação da qualidade da água se dá por análises que permitem quantificar alterações na sua composição física, química e biológica. Com esse propósito, a Resolução CONAMA $357 / 2005$ estabelece limites para os parâmetros de qualidade dos cursos de água doce no país, bem como dispõe sobre seu enquadramento e possíveis usos. ${ }^{5}$

Porém, a grande extensão e volume de água doce que corta o território brasileiro (cerca de $13,8 \%$ do deflúvio médio mundial) dificulta a fiscalização. ${ }^{6}$ Para a Agência Nacional de Águas (ANA), o envolvimento da população em programas comunitários é extremamente importante e vem de encontro às ações de fiscalização, pois promove a conscientização da população sobre sua responsabilidade na manutenção da qualidade dos rios. Nesse sentido, há um grande incentivo para o desenvolvimento de metodologias que auxiliem no processo de universalização e apropriação do conhecimento. $^{7}$

Nesse contexto surgiu a motivação para a realização deste trabalho, cujo objetivo é apresentar uma ferramenta para a abordagem interdisciplinar de conteúdos de química, biologia, física e geografia na formação de alunos do ensino médio e superior sobre a qualidade dos recursos hídricos, com o propósito de desenvolver nos estudantes uma visão holística do problema e um olhar crítico sobre o seu papel como cidadão.

\section{A interdisciplinaridade como estratégia de ensino}

A análise de água como meio de promover a conscientização ambiental é uma prática bastante utilizada. É o caso do programa World Water Monitoring Challenge, uma organização internacional sem fins lucrativos que desde 2002 incentiva o comprometimento de cidadãos com a qualidade da água de sua região, por meio do monitoramento e compartilhamento de informações sobre os corpos d'água. ${ }^{8}$

No Brasil diversos pesquisadores vêm testando a utilização da prática de análise de água no envolvimento da comunidade em debates ambientais, ${ }^{9-12}$ e todos relatam benefícios socioambientais decorrentes da percepção desenvolvida pela população, por meio da conscientização sobre a importância desse recurso e das responsabilidades de cada indivíduo. Além disso, quando se consegue conciliar 0 processo de aprendizagem com uma forte contextualização social, com significado para o indivíduo, os resultados são potencializados. ${ }^{12}$ Sendo assim, ao relacionar diferentes ramificações das áreas do conhecimento (química, biologia, física e geografia) com debates sobre meio ambiente, trabalham-se não somente conceitos básicos do saber, mas também as capacidades necessárias para aplicá-los no dia-a-dia no exercício da cidadania.

O relatório "Cuidando das águas", elaborado pela ANA, aponta que o processo de educação e conscientização ambiental tem como meta principal promover mudanças sociais, no indivíduo e na coletividade. $O$ documento mostra ainda que é importante demonstrar para a comunidade os problemas existentes e indicar soluções possíveis e viáveis para a sua região. Dessa forma, trabalha-se o senso crítico do cidadão, tornando-o mais apto para conduzir suas atitudes baseadas em uma consciência ecológica. ${ }^{7}$

Porém, na educação convencional 
raramente se utiliza uma abordagem CTSA (Ciência, Tecnologia, Sociedade e Ambiente), que busca desenvolver o vocabulário e a percepção do indivíduo por meio de procedimentos alternativos de ensino em uma visão integralizada do conhecimento. ${ }^{11}$

No ensino convencional de química, por exemplo, os conceitos são apresentados de forma não contextualizada, o que dificulta, muitas vezes, a correlação do tema "água" com aspectos sociais, políticos, históricos, culturais e geográficos. A explicação para esse comportamento pode estar apoiada no fato de que os saberes são separados em conteúdos distintos (ou disciplinas), impedindo que o estudante desenvolva a habilidade de integrar assuntos aprendidos em aula. Por sua vez, isso pode gerar o desinteresse do estudante na assimilação de conhecimentos estritamente teóricos e dificultar a compreensão de conceitos mais complexos. ${ }^{11}$

Quando o ensino é abordado sob uma ótica holística em torno de uma determinada questão (como é o caso da qualidade da água), tende a despertar questionamentos nos estudantes, sobre as relações entre o homem e o meio em que ele vive e sua relação com os demais seres vivos. Essa proposta traz enormes benefícios quando trabalhada em conjunto com a experimentação e a vivência do estudante, bem como características sociais e culturais locais. $^{13}$

\section{Práticas de ciências em uma abordagem interdisciplinar}

Encontra-se relatado na literatura um estudo com a aplicação de mapeamento ambiental em saídas de campo, que trouxe não somente percepções ampliadas dos aspectos ambientais, mas também proporcionou a identificação de diferentes problemas vivenciados cotidianamente pelas crianças em seus bairros. A partir do diagnóstico traçado pelos alunos, foram realizadas atividades de educação comunitária, desde construções de maquetes até mutirões de limpeza. Além disso, essa experiência fez com que os alunos desenvolvessem um sentimento de pertencimento e integração ao ambiente local, ao mesmo tempo em que se identificaram como parte do grupo. 0 mesmo autor destaca que é indispensável promover a inserção do conhecimento teórico nas atividades práticas desenvolvidas junto à comunidade. $^{13}$

Em outro estudo, desenvolvido na cidade de São Carlos, interior do Estado de São Paulo, alunos do ensino fundamental e ensino médio (13 e 17 anos) foram estimulados a correlacionar teoria e prática em atividades de verificação de parâmetros físico-químicos da água (temperatura, $\mathrm{pH}$, oxigênio dissolvido e condutividade elétrica), questões socioculturais (a partir de entrevistas com moradores) e geográficas da região em aulas de Ciências e Biologia. $O$ objetivo da pesquisa era testar uma proposta educativa, sob a abordagem CTSA. ${ }^{10}$ Os resultados mostraram que os alunos conseguiram utilizar os conceitos científicos de maneira bastante satisfatória quando foram requisitados, gerando inclusive debates e argumentos bem consistentes em sala de aula. No ponto de coleta de água com o menor valor de oxigênio dissolvido (OD), os estudantes identificaram uma possível correlação com o descarte inadequado de esgoto doméstico naquele trecho. Além disso, ao final do projeto, os alunos puderam contribuir com mais informações sobre a qualidade da água no córrego Paraíso (local de coleta de água) e sobre a bacia hidrográfica onde ele está inserido, além de expandirem para os seus familiares o conhecimento por eles vivenciado. ${ }^{10}$

Propostas semelhantes também foram estudadas em outras partes do país. Em Belo Horizonte, oito cursos de água foram analisados por alunos do ensino médio e fundamental para verificar características físico-químicas e possíveis usos da água, de acordo com a legislação ambiental. Nessa 
campanha, os alunos observaram também a presença de resíduos sólidos e de animais na vizinhança dos pontos de coleta e identificaram quais os usos da água para a comunidade na época da realização do trabalho. Como resultado, os alunos se sentiram motivados por participarem de pesquisas sobre problemas reais de suas comunidades, o que repercutiu na aprendizagem e desempenho dos alunos em sala de aula. ${ }^{14}$

Na cidade de Ponta Grossa, no Estado do Paraná, estudantes do ensino médio profissionalizante (curso técnico em meio ambiente) realizaram coletas de água em um córrego próximo à escola. $\mathrm{O}$ autor destaca que os alunos não possuíam experiência prática em analisar características de um corpo d'água, embora fossem estudantes na área de meio ambiente. Um diferencial desse trabalho foi a utilização de uma ferramenta computacional (Google Earth) para a escolha do córrego. Ao final da pesquisa foram aplicados questionários com perguntas sobre a importância do monitoramento da qualidade de cursos d'águas e a forma realizar as análises. As respostas dos alunos foram bem elaboradas, levantando inclusive questões de ordem política. Para os estudantes que participaram dessa pesquisa, as atividades práticas, aliadas à utilização da ferramenta do Google Earth, trouxeram grandes benefícios para sua formação profissional. ${ }^{15}$

Um projeto que ganha destaque nacional é o "Programa Agente das Águas", desenvolvido pelo Laboratório de Avaliação e Promoção da Saúde Ambiental da Fundação Oswaldo Fiocruz, com a participação do biólogo Daniel Forsin Buss, que atua em campanhas comunitárias de educação ambiental e monitoramento da qualidade de cursos d'água. ${ }^{16} \mathrm{~A}$ característica peculiar desse projeto é o método adotado nas atividades de envolvimento comunitário, que utiliza o Índice Comunitário para Voluntários (IBVol). ${ }^{9}$ O programa oferece um curso simplificado de coleta e identificação de macroinvertebrados para os participantes. Finalizado o curso, os voluntários vão a campo e realizam coletas de organismos, que são identificados e utilizados na avaliação da qualidade da água pelo índice IBVol. Esse índice consiste no atributo de valores entre 1 e 5 para cada grupo de macroinvertebrados, sendo que os mais sensíveis recebem os valores mais altos. ${ }^{9,16}$

A utilização de macroinvertebrados como bioindicador apresenta várias vantagens, por ser um grupo ubíquo, de relativa facilidade de identificação (pelo índice IBVol) e de baixo custo. Outro aspecto positivo é o comportamento diferenciado de algumas espécies de frente a poluentes diversos, isto é, algumas espécies possuem sensibilidade a certos contaminantes ao mesmo tempo em que são resistentes a outros. ${ }^{6}$

Diante das práticas aqui apresentadas fica evidente a importância da inserção de atividades práticas de verificação da qualidade dos corpos hídricos juntamente com as aulas teóricas expositivas (ensino formal) de conteúdos disciplinares. Essa proposta é bastante promissora, sobretudo no processo de conscientização e formação de estudantes do ensino médio e fundamental, que, na maioria das vezes, não detêm conhecimento e maturidade suficiente para correlacionar assuntos vistos em sala de aula com a realidade em seus bairros. Entretanto, os projetos que utilizam atividades práticas aliadas ao mapeamento ambiental, identificados na literatura, não dispõem de uma ferramenta estruturada logicamente e organizada em uma abordagem interdisciplinar, capaz de integrar professores de diferentes áreas do conhecimento em suas aulas. Pelo contrário, são práticas isoladas a partir de iniciativas independentes. Esta é, portanto, a contribuição deste trabalho inédito.

Além disso, a consolidação da abordagem aqui proposta pode contribuir para a gestão mais eficiente dos recursos hídricos, considerando-se o momento atual de escassez de água, pela expansão do levantamento de dados de monitoramento da qualidade a partir de aulas práticas, sempre sob a supervisão de professores treinados. 


\section{Desenvolvimento da proposta do trabalho}

Este trabalho foi estruturado em duas partes: 1) levantamento de parâmetros químicos, físicos, biológicos, geográficos e de observação, para investigar a qualidade da água (requer a participação do aluno na obtenção dos dados em rios de sua comunidade); 2) armazenamento e análise dos dados obtidos (integra a prática e o conteúdo teórico).

Para definir os parâmetros químicos foi realizado um cruzamento de informações da Resolução CONAMA 357 (Conselho Nacional do Meio Ambiente) de 2005, no tocante à qualidade e enquadramento dos corpos hídricos, e do Índice de Qualidade de Água (IQA) ${ }^{15}$ Os parâmetros selecionados foram: cloreto, cloro livre residual, demanda bioquímica de oxigênio (DBO), demanda química de oxigênio (DQO), dureza total, ferro, nitrato, nitrito, nitrogênio amoniacal e total, ortofosfato, oxigênio dissolvido, $\mathrm{pH}$, fósforo total. Para os conteúdos de biologia foram considerados os macroinvertebrados utilizados no cálculo do Índice Biológico para Voluntários (IBVol) e coliformes fecais, presente na Resolução CONAMA 357 e no IQA. Os aspectos físicos selecionadas foram: temperatura, turbidez e resíduos totais.

Os parâmetros químicos podem ser analisados por meio de kits comerciais de qualidade da água, de baixo custo, ou de material de análise fornecido em campanhas de educação ambiental, como o projeto World Water Monitoring Challenge. Esses kits comumente utilizam o método colorimétrico com cartela comparativa de cores para determinação da concentração dos parâmetros de qualidade da água analisados. $^{8}$

Por fim, foi considerada relevante a localização espacial do corpo hídrico estudado (uso de GPS e recursos do GoogleEarth ${ }^{\circledR}$ ) para o aspecto geográfico e a caracterização da vizinhança do curso de água (presença de mata ciliar, resíduos sólidos, solo compactado, odor, eutrofização, olhos e graxas, espumas, animais aquáticos, atividades humanas) como aspecto de observação. ${ }^{15}$

Para o armazenamento de dados foi utilizada uma planilha eletrônica (Excel ou similar), por sua funcionalidade (atende a todas as necessidades do usuário), disponibilidade de recursos (adequada para inserção de informações e equações), simplicidade de uso (fácil utilização) e acessibilidade a qualquer escola que disponha de um computador minimamente configurado (compatível com o software Microsoft Office ou OpenOffice). Além disso, essa ferramenta dispensa a necessidade de acesso à World Wide Web (rede de internet), pois sua estrutura disponibiliza todo conteúdo necessário para integrar a aula prática e os conteúdos teóricos para discussão em sala de aula. Por fim, a ferramenta do OpenOffice é gratuita e, por ser aberta, pode ser modificada e ajustada de acordo com a necessidade e desejo do professor.

\section{Resultados e discussão}

A estrutura da ferramenta proposta neste trabalho foi definida a partir da análise de trabalhos reportados na literatura que relatam a utilização de atividades práticas na sensibilização de estudantes sobre a importância da conservação da qualidade dos cursos d'água em suas comunidades.,10,14-16 Com base nessa análise preliminar, foram consideradas relevantes as seguintes categorias de informação sobre o corpo hídrico: aspectos químicos e físicos; aspectos biológicos; caracterização da vizinhança. A quantificação e a qualificação dessas categorias compreende 0 foco de investigação e levantamento de dados sobre o curso hídrico por parte dos estudantes.

Além dos aspectos quantificáveis e observáveis, considerou-se importante que a 
ferramenta estimulasse nos estudantes a integração entre atividade prática e conteúdo teórico. Sendo assim, foram criadas outras três categorias de informação, sendo elas: glossário com conceitos correlatos à qualidade da água doce; legislação que norteia os valores limites para parâmetros químicos e físicos e características observáveis; sugestão de material para estudo complementar sobre recursos hídricos.

O Quadro 1 resume a estrutura da ferramenta, que engloba seis etapas e cada etapa corresponde a uma aba da planilha eletrônica. As três primeiras etapas compreendem: 1) inserção dos valores obtidos na análise dos parâmetros químicos da água e cálculo do IQA; 2) inserção dos valores obtidos na quantificação dos macroinvertebrados e cálculo do IBVol; 3) inserção de características físicas e aquelas observadas na vizinhança do trecho do rio analisado. As últimas três etapas não preveem entrada de dados de campo; elas armazenam os seguintes conteúdos: 4) glossário sobre temas abordados nas etapas 1, 2 e 3; 5) informações da Resolução CONAMA 357 ; 6) material sugerido para estudo complementar. $\mathrm{Na}$ ferramenta proposta, as abas correspondentes às etapas de entrada de dados (etapas 1, 2 e 3) possuem um pequeno texto de introdução, com o respectivo objetivo e metodologia empregada. Os detalhes da configuração de cada etapa são apresentados a seguir.

Quadro 1. Resumo das principais ações definidas para a ferramenta

\begin{tabular}{|c|c|c|}
\hline & ENTRADA DE DADOS & FUNÇÕES \\
\hline \multirow{4}{*}{$\begin{array}{l}\text { Etapa } 1 \\
\text { (aba 1) }\end{array}$} & Classe do rio (1, 2, 3 ou 4) & $\begin{array}{c}\text { Define a classe do corpo hídrico que será } \\
\text { analisado (necessário para comparação com a } \\
\text { legislação) }\end{array}$ \\
\hline & $\begin{array}{l}\text { Tipo de ambiente aquático (lêntico, } \\
\text { intermediário ou lótico) }\end{array}$ & $\begin{array}{l}\text { Define o tempo de permanência da água no } \\
\text { corpo hídrico (necessário para comparação } \\
\text { com a legislação) }\end{array}$ \\
\hline & Altitude do corpo hídrico & $\begin{array}{l}\text { Define a altitude do corpo hídrico em relação } \\
\text { ao nível do mar (necessário para comparação } \\
\text { com a legislação) }\end{array}$ \\
\hline & $\begin{array}{c}\text { Concentração dos parâmetros (cloreto, } \\
\text { cloro livre residual, coliformes fecais, } \\
\text { DBO, DQO, dureza total, ferro, nitrato, } \\
\text { nitrito, nitrogênio amoniacal, } \\
\text { ortofosfato, oxigênio dissolvido, pH, } \\
\text { turbidez) }\end{array}$ & $\begin{array}{c}\text { Apresenta o resultado das análises físico- } \\
\text { químicas e biológicas realizadas no corpo } \\
\text { hídrico }\end{array}$ \\
\hline $\begin{array}{l}\text { Etapa } 2 \\
\text { (aba 2) }\end{array}$ & $\begin{array}{l}\text { Quantificação de macroinvertebrados } \\
\text { (presença ou ausência) }\end{array}$ & $\begin{array}{c}\text { Indica a presença ou ausência do respectivo } \\
\text { grupo de macroinvertebrados, segundo o } \\
\text { índice }\left.\right|_{\mathrm{BV} V \mathrm{I}^{9}}{ }^{9}\end{array}$ \\
\hline \multirow[b]{2}{*}{$\begin{array}{l}\text { Etapa } 3 \\
\text { (aba 3) }\end{array}$} & $\begin{array}{c}\text { Caracterização da vizinhança do rio por } \\
\text { observação (presença ou ausência) }\end{array}$ & $\begin{array}{c}\text { Indica as características físicas e de } \\
\text { observação na vizinhança do rio }\end{array}$ \\
\hline & $\begin{array}{c}\text { Entrada de palavra-chave (anfíbios, } \\
\text { odor, espuma, eutrofização, mata ciliar, } \\
\text { óleos e graxas, peixes, solo compactado, } \\
\text { agropecuária, depósito de lixo, despejos } \\
\text { industriais e domésticos) }\end{array}$ & $\begin{array}{l}\text { Apresenta os conceitos relativos a } \\
\text { parâmetros de observação, conforme o } \\
\text { termo de busca, e sugere temas para } \\
\text { discussão do assunto em sala de aula }\end{array}$ \\
\hline
\end{tabular}




\begin{tabular}{|c|c|c|}
\hline $\begin{array}{c}\text { Etapa 4 } \\
\text { (aba 4) }\end{array}$ & Não há entradas & $\begin{array}{c}\text { Apresenta o conceito relativo ao termo de } \\
\text { busca e sua correlação com a qualidade da } \\
\text { água (glossário) }\end{array}$ \\
\hline $\begin{array}{c}\text { Etapa 5 } \\
\text { (aba 5) }\end{array}$ & Não há entradas & $\begin{array}{r}\text { Apresenta o enquadramento dos corpos } \\
\text { hídricos pela Resolução CONAMA 357, os } \\
\text { limites dos parâmetros de qualidade e os } \\
\text { usos da água previstos para cada classe }\end{array}$ \\
\hline $\begin{array}{c}\text { Etapa 6 } \\
\text { (aba 6) }\end{array}$ & Não há entradas & $\begin{array}{c}\text { Apresenta links e sugestão de material para } \\
\text { estudo complementar sobre os temas } \\
\text { abordados nas etapas 1, 2 e 3 }\end{array}$ \\
\hline
\end{tabular}

5.1. Etapa 1: Caracterização físicoquímica e biológica da água

A configuração utilizada na etapa 1 permite ao aluno comparar resultados de análises químicas, físicas e biológicas ${ }^{1}$ de campo com a legislação (Resolução CONAMA 357) e determinar o valor do IQA no ponto de coleta. A classe do corpo hídrico $(1,2,3$ ou 4), o tipo de escoamento (lêntico, lótico ou intermediário) e a altitude do corpo d'água são informações obrigatórias. A Figura 1 mostra a primeira etapa da ferramenta proposta neste trabalho, com destaque em vermelho para os campos que devem ser inicialmente preenchidos nesta etapa.

Na coluna destacada em azul o aluno deve inserir os valores de cada parâmetro analisado em campo; esses valores serão cruzados com os valores do banco de dados da legislação (etapa 6), retornando ao aluno a condição do corpo d'água, isto é, a conformidade ou não com a legislação. Quando os valores dos nove parâmetros de qualidade do IQA são inseridos (oxigênio dissolvido, temperatura, nitrogênio total, fósforo total, coliformes fecais, demanda bioquímica de oxigênio, turbidez, $\mathrm{pH}$ e sólidos totais), o IQA é calculado e o valor obtido pode ser comparado com as faixas de qualidade da água (péssima a ótima), como mostra a Figura 2.

\footnotetext{
1 Neste trabalho foi utilizado o kit ambiental de análises físico-químicas da água (código 6681) do fabricante Alfakit (http://www.alfakit.com.br/).
}

A seleção dos parâmetros mais apropriados para compor a ferramenta foi feita com base na lista de parâmetros de qualidade de kits de análise de água comumente utilizados e nos nove parâmetros do IQA. No total foram incluídos 19 parâmetros físico-químicos e biológicos, todos passíveis de serem mensurados a partir de kits comerciais.

\subsection{Etapa 2: Determinação do Índice} IBVol

A etapa 2 da ferramenta apresenta os campos para determinação do índice IBVol, utilizando-se 16 grupos de macroinvertebrados. Nessa etapa o usuário deve identificar a presença ou a ausência de cada grupo de macroinvertebrado (Figura 3). Os grupos taxonômicos possuem uma imagem representativa e seu correspondente peso, ${ }^{16}$ para facilitar a identificação pelo aluno. O índice IBVol é o resultado da soma dos pesos de todos os grupos presentes e esse valor será comparado com as faixas do índice, que variam de ruim a excelente. Nesta etapa, assim como na etapa anterior, ferramenta incluí campos para análises em triplicata, para que o professor possa abordar em suas aulas a aplicação de estatística básica e discutir a interpretação dos resultados com os alunos. 


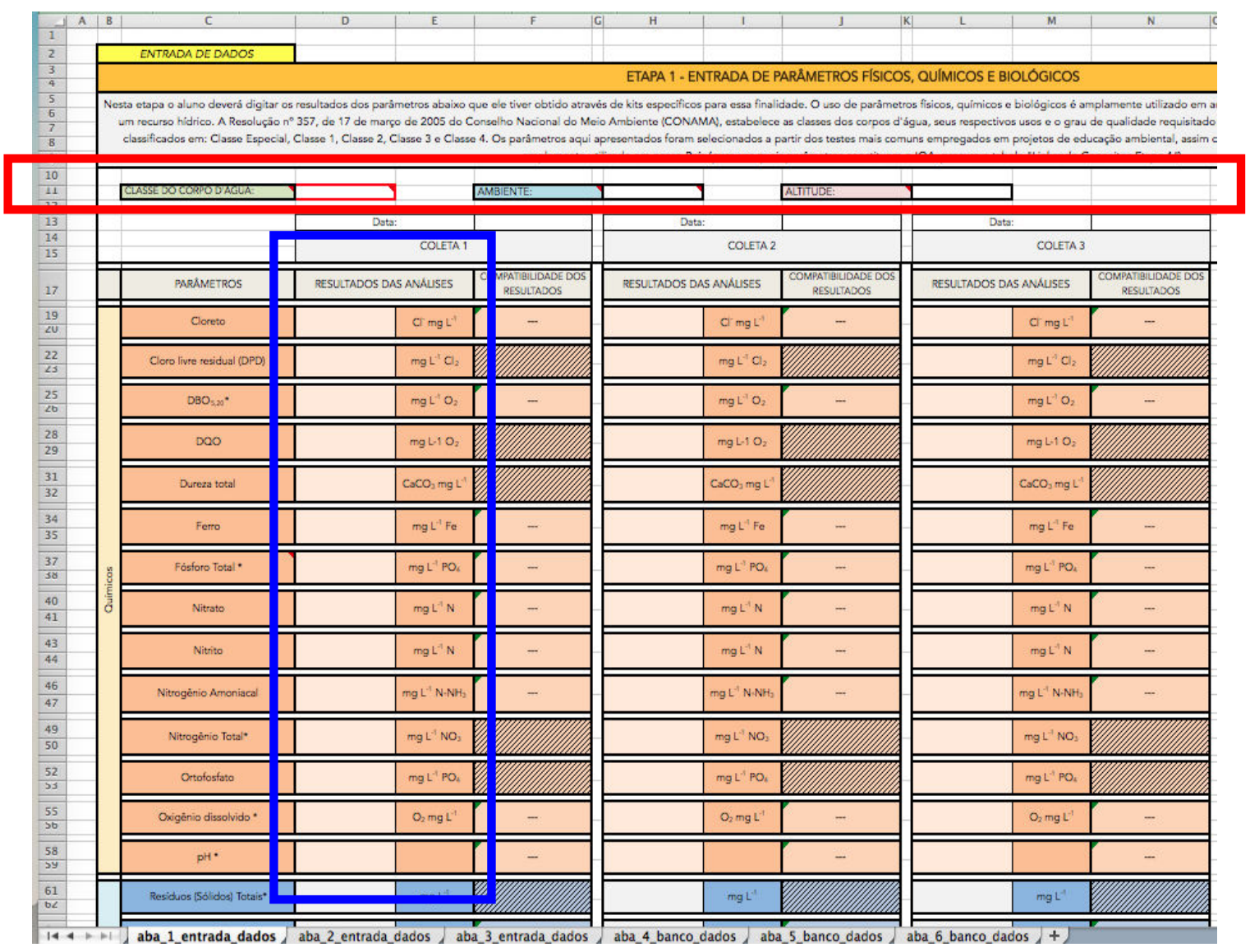

Figura 1. Entrada de dados para os parâmetros físicos, químicos e coliformes

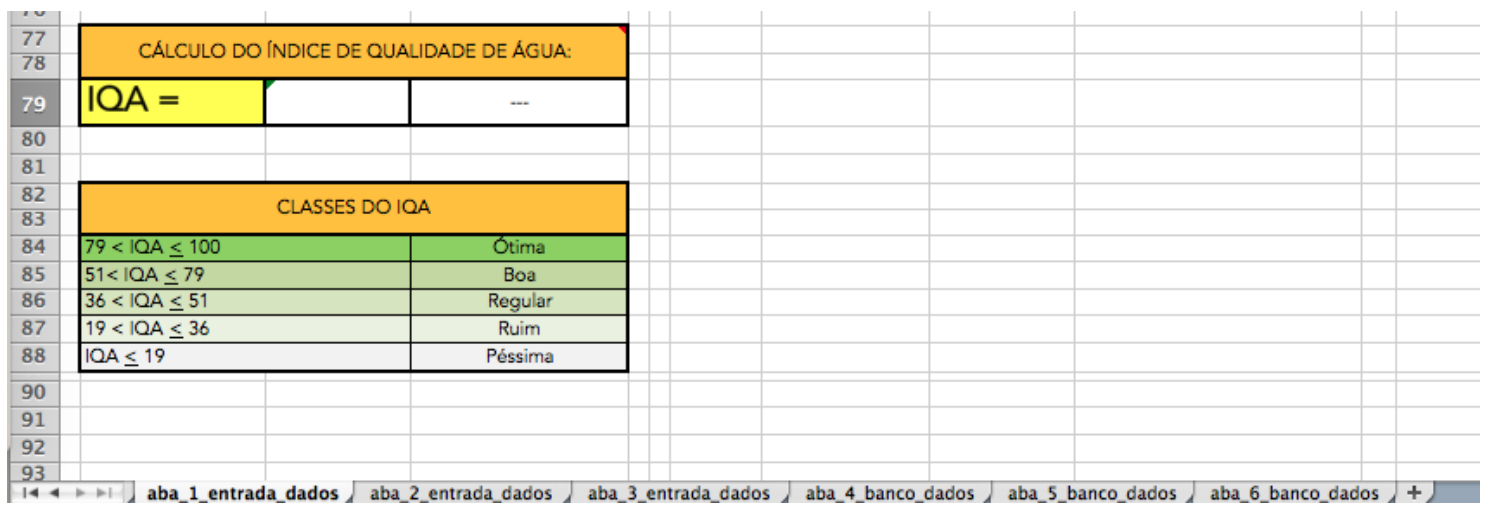

Figura 2. Determinação do IQA a partir de amostras de água 


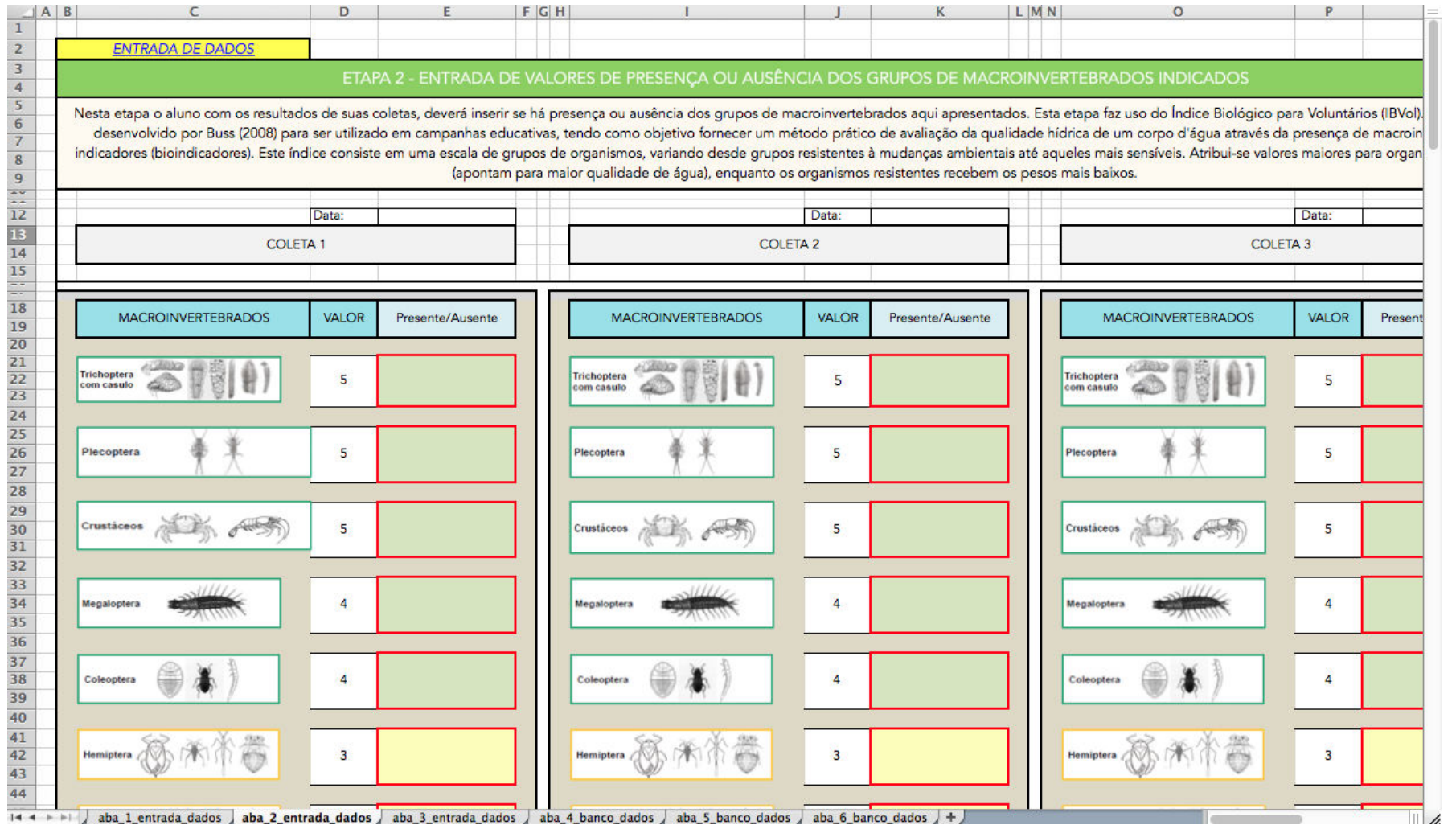

Figura 3. Campo para registrar presença ou ausência dos diferentes grupos de macroinvertebrados utilizados no IBVol

\subsection{Etapa 3: Caracterização da vizinhança do corpo hídrico}

A etapa 3 compreende a análise de um conjunto de características ambientais (mata ciliar, solo compactado, odor, eutrofização, resíduos, óleos e graxas, espumas, peixes, anfíbios, atividades agropecuárias, depósito de resíduos urbanos, despejos industriais ou domésticos), selecionadas a partir da legislação, cujo propósito é desenvolver a percepção crítica do aluno sobre o impacto de atividades de vizinhança na qualidade do corpo hídrico (Figura 4). Uma tabela com a descrição conceitual das 12 características de observação avaliadas foi incluída nessa etapa.

Além de identificar presença ou ausência das 12 características ambientais selecionadas, o usuário pode especificá-las, em campos indicados na ferramenta, e incluir várias outras informações que julgar relevantes para a discussão em sala de aula (como proximidade, tipologia, quantidade, entre outras), bem como pode ampliar essa lista com outros aspectos de ocorrência tipicamente local ou regional.

\subsection{Etapa 4: Glossário}

Comumente, as análises ambientais possuem vocabulário próprio, por vezes desconhecido dos alunos. Por essa razão, verificou-se a necessidade de incluir um glossário na ferramenta, onde constam conceitos sobre os diversos termos utilizados (Figura 5). Dessa forma, pretende-se aliar o desenvolvimento prático ao conhecimento teórico indispensável na formação do aluno. Em razão da versatilidade do software utilizado (planilha Excel ou similar) é possível adicionar um número ilimitado de conteúdos no glossário, a critério do professor da disciplina. 


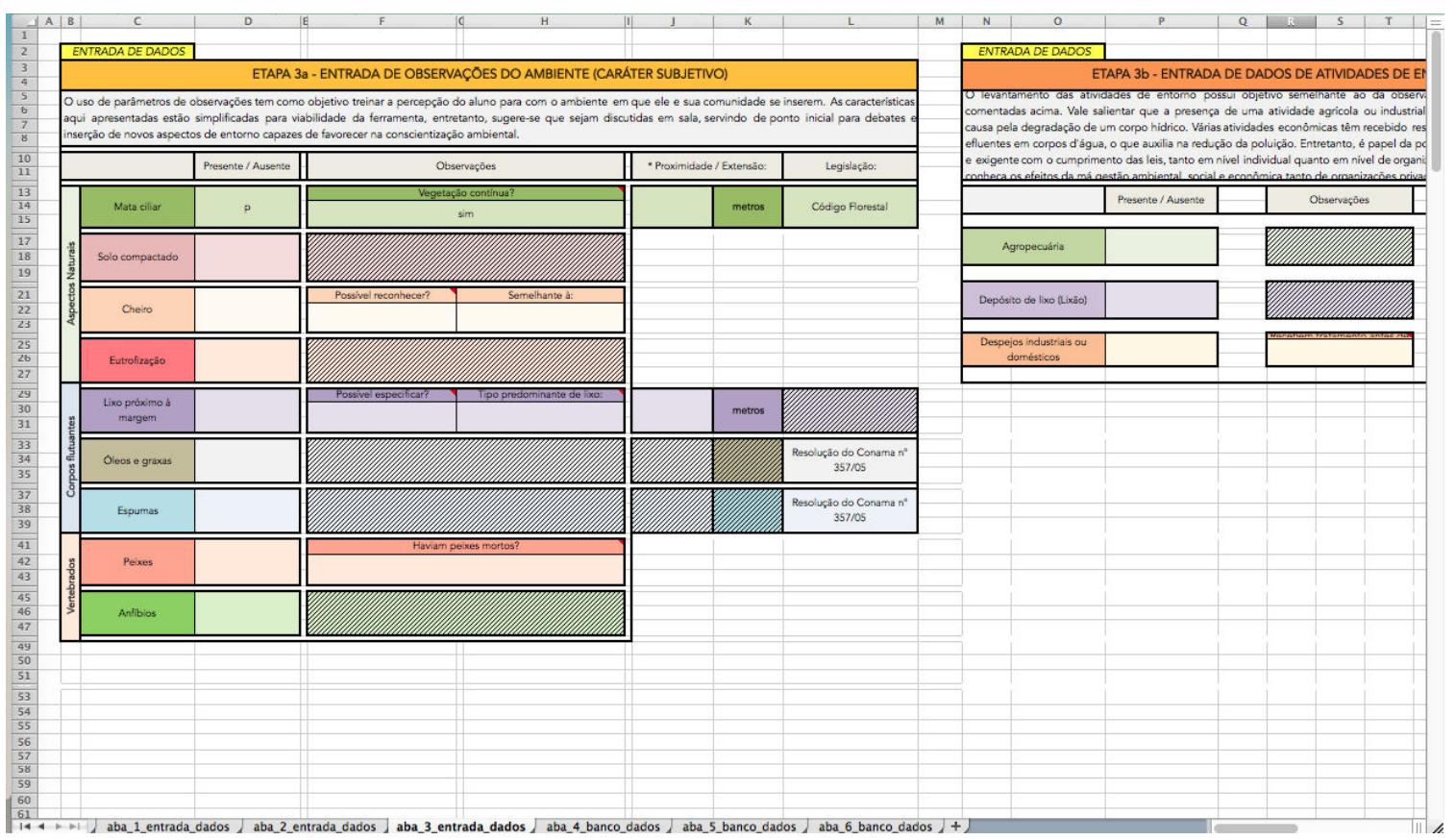

Figura 4. Campo para caracterização da vizinhança do corpo hídrico

\begin{tabular}{|c|c|c|c|c|}
\hline$\triangle \mathrm{A}$ & B & c & D & E \\
\hline$\frac{1}{2}$ & & ETAPA 4 - GLOSSÁRIO & & \\
\hline 3 & AA & & & \\
\hline$\frac{4}{5}$ & Agropecuśria & 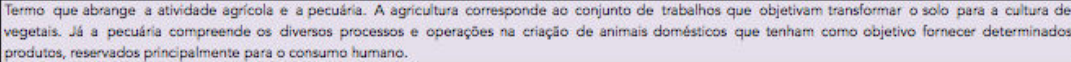 & & \\
\hline $\begin{array}{l}7 \\
8 \\
9\end{array}$ & Agas & 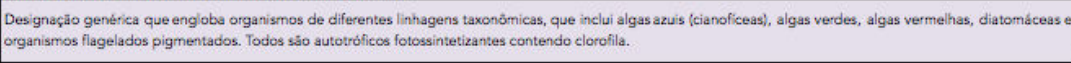 & & \\
\hline $\begin{array}{l}\frac{10}{11} \\
12\end{array}$ & Algas azuis & 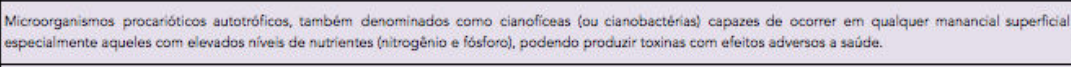 & & \\
\hline $\begin{array}{l}13 \\
15 \\
15\end{array}$ & Ambiente intermediario & Ambiente intermedíario, com tempo de residéncia entre 2 e 40 dias, e tributários diretos de ambiente léntica. (Conama n* 357/05) & & \\
\hline$\frac{16}{17}$ & Ambiente lêntico & Ambiente que se refere à água parada, com movimento lento ou estagnado. (Conama n $n^{\circ} 357 / 0$ ) ) & & \\
\hline $\begin{array}{l}19 \\
20 \\
21\end{array}$ & Ambiente lótico & Ambiente relativo a gguas continentais moventes. (Conama $n^{\circ} 357 / 05$ ) & & \\
\hline$\frac{22}{23}$ & Amớnia & 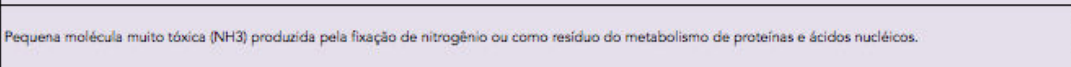 & & \\
\hline$\frac{25}{26}$ & Anfibios & Membros da Classe Amphibia de tettápodes, incluindo salamandras, sapos e cobras-cegas. & & \\
\hline$\frac{27}{28}$ & B\# & & & \\
\hline $\begin{array}{l}29 \\
30 \\
31\end{array}$ & Bioindicadores & 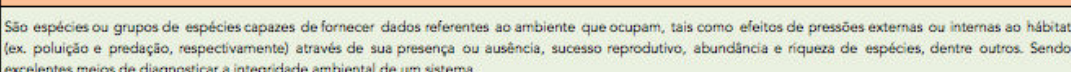 & & \\
\hline 32 & & & & \\
\hline 33 & $\mathrm{CA}_{\mathrm{B}}$ & & & \\
\hline $\begin{array}{l}37 \\
38 \\
39\end{array}$ & Categoria taxonómica & Também denominada táxon, representa a unidade taxonỏmica nomeada em qualquer nivel de classificą̧̧ẩ. & & \\
\hline $\begin{array}{ll}40 \\
41 \\
42\end{array}$ & Cheiro da agua & 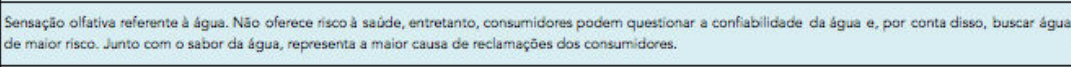 & & \\
\hline 43 & Casse de qualidade & Conjunto de condiç̧̄es e pactröes de qualidade de agua necessastios ao atendimento dos usos preponderantes, atuais ou futuros. & & \\
\hline$\frac{46}{47}$ & Cassificą̧̧̄o dos corpos d’água & Qualificą̧ăo das águas doces, sal obras e salinas en funçăo dos usos preponderantes (sistema de classes de qualidade) atuais e futuros. & & \\
\hline $\begin{array}{ll}49 \\
50 \\
51\end{array}$ & Coreto & 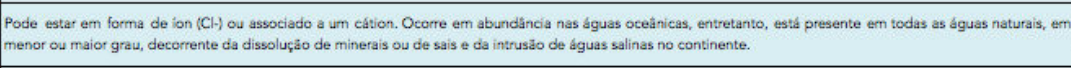 & & \\
\hline $\begin{array}{l}52 \\
53 \\
54\end{array}$ & Coro livere resdual (DPD) & Chama-se cioro residual live o cloro presente na água nas formas do ácida hipocloroso $(\mathrm{HOC})$ ou do ion hipoclorito $(\mathrm{OCl}-\mathrm{-}$. & & \\
\hline 55 & & & & \\
\hline
\end{tabular}

Figura 5. Glossário de termos técnico-científicos 


\subsection{Etapa 5 e Etapa 6: Legislação e material suplementar}

$\mathrm{Na}$ etapa 5 foram disponibilizadas as principais informações sobre a Resolução CONAMA 357, que trata do enquadramento dos corpos hídricos, dos valores limites para os parâmetros de qualidade da água e estabelece os usos múltiplos da água de acordo com a sua qualidade. Por fim, na última etapa da ferramenta o aluno tem acesso a uma lista de referências e links sugeridos sobre qualidade da água, que podem ser utilizados nas aulas teóricas.

É importante destacar que todas as etapas da ferramenta apresentadas neste trabalho podem ser modificadas e adaptadas segundo as necessidades e especificidades das diversas realidades e características regionais do país. Além disso, os autores identificam que a ferramenta tem potencial para ser convertida em um programa computacional gráfico interativo, que poderá ser mais atrativo para os alunos.

Por fim, os autores deste trabalho se comprometem a disponibilizar gratuitamente cópias da ferramenta para todos os interessados.

\section{Conclusão}

A ferramenta apresentada neste estudo foi construída para proporcionar ao estudante a aquisição do conhecimento teórico ao mesmo tempo em que desenvolve a experimentação prática, com o propósito de consolidar conceitos recebidos em sala de aula e despertar o aluno para a importância da conservação da qualidade dos corpos hídricos de sua comunidade.

Outros aspectos observados foram: facilidade de utilização da ferramenta (sistema intuitivo), acessibilidade a qualquer computador minimamente configurado (software Microsoft Office ou OpenOffice), dispensa a necessidade de internet, pode ser modificado de acordo com as especificidades regionais do país (sistema aberto), pode ser atualizada sem qualquer custo, desenvolve no aluno uma visão interdisciplinar e global do problema (poluição das águas) de grande importância na discussão de soluções para os futuros profissionais da área, disponibiliza questões para discussões sobre recursos hídricos conduzidas pelo professor em sala de aula (com base em uma seleção minuciosa de temas da atualidade), os kits comerciais de análise química da água podem ser facilmente adquiridos a baixo custo (método colorimétrico com cartela comparativa de cores para determinação da concentração dos parâmetros de qualidade da água analisados).

\section{Referências Bibliográficas}

${ }^{1}$ Black, J. G.; Microbiologia: Fundamentos e Perspectivas, 4a. ed., Rio de Janeiro: Guanabara Koogan, 2002.

${ }^{2}$ Pereira, R. S. Identificação e caracterização das fontes de poluição em sistemas hídricos. Revista Eletrônica de Recursos Hídricos 2004, 1, 20. [Link]

${ }^{3}$ Miller Jr, G. T.; Ciência Ambiental, 11a. ed., São Paulo: Thomson Learning, 2006.

${ }^{4}$ Brasil. Política Nacional Do Meio Ambiente. Lei $n^{\circ} 9.433$, de 8 de janeiro de 1997. Institui a política nacional de recursos hídricos, cria o sistema nacional de gerenciamento de recursos hídricos, 1997. [Link]

${ }^{5}$ Brasil. Conselho Nacional do Meio Ambiente. Resolução № 357, de 17 de março de 2005. dispõe sobre a classificação dos corpos de água e diretrizes ambientais para o seu enquadramento, bem como estabelece as condições e padrões de lançamento de efluentes, e dá outras providências, 2005. [Link]

${ }^{6}$ Buss, D. F.; Baptista, D. F.; Nessimian, J. L. Bases conceituais para a aplicação de biomonitoramento em programas de avaliação da qualidade da água de rios. Caderno De Saúde Pública, Rio De Janeiro 2003, 19, 465. [CrossRef] 
${ }^{7}$ Brasil. Agência Nacional das Águas. Cuidando das Águas: soluções para melhorar a qualidade dos recursos hídricos. Agência Nacional das Águas; Programa das Nações Unidas para o Meio Ambiente, Brasília, 2011. [Link]

${ }^{8}$ World Water Monitoring Challenge, 2015. [Link]

${ }^{9}$ Buss, D. F. Desenvolvimento de um índice biológico para uso de voluntários na avaliação da qualidade da água de rios. $O$ Ecologia Brasiliensis 2008, 12, 520.

${ }^{10}$ Zuin, V. G.; loriatti, M. C. S.; Matheus, C. E. O emprego de parâmetros físicos e químicos para a avaliação da qualidade de águas naturais: Uma proposta para a educação química e ambiental na perspectiva CTSA. Química Nova na Escola 2009, 31. [Link]

${ }^{11}$ Soares, L. F.; Lima, M. A. L.; Couto, A. K. C.; Silva, K. C. S.; Sampaio, C. G.; Gomes, F. H. F. Análise de água: uma abordagem CTSA à luz dos documentos oficiais da prática docente no Brasil. VII Congresso Norte Nordeste de Pesquisa e Inovação, Palmas, 2012. [Link] ${ }^{12}$ Oliveira, R.; Irazusta, S. P. Aprendizagem significativa, educação ambiental e ensino de química: a experiência realizada em uma escola pública (Anais eletrônicos). VII Encontro Pesquisa em Educação Ambiental, São Paulo, 2013. [Link]

${ }^{13}$ Tozoni-Reis, M. F. C. A construção coletiva do conhecimento e a pesquisa-ação participativa: compromissos e desafios. Revista Pesquisa em Educação Ambiental 2007, 2, 89. [Link]

${ }^{14}$ Guimarães, A. C. Desenvolvimento de um trabalho de campo como estratégia didática para o ensino de química na educação de jovens e adultos (resumo). VII Encontro Paulista de Ensino em Química, São Paulo, 2013. [Link]

${ }^{15}$ Campos, S. X.; Freire, L. I. F.; Scheffer, E. W. O. ; Milaré, T.; Martins, P. H. M. L.; Zittel, R. Oficina pedagógica ambiental: proposição de um IQA e utilização do software Google Earth em um curso técnico integrado em meio ambiente. Educar em Revista 2011, 40, 35. [Link]

${ }^{16}$ Cichoski, C.; Dissertação de Mestrado, Universidade de São Paulo, 2013. [Link] 